\title{
Use of Healthy-Donor Granulocyte Transfusions to Treat Infections in Neutropenic Patients with Myeloid or Lymphoid Neoplasms: Experience in 74 Patients Treated with 373 Granulocyte Transfusions
}

\author{
Amar Safdar a,b Gilhen Rodriguez ${ }^{a} \quad$ Jorge Zuniga ${ }^{a} \quad$ Fadi Al Akhrass $^{a}$ \\ Anupam Pande ${ }^{a}$ \\ ${ }^{a}$ The University of Texas MD Anderson Cancer Center, Houston, Tex., and ${ }^{\mathrm{b}}$ New York University Langone Medical \\ Center, New York, N.Y., USA
}

\section{Key Words}

Granulocyte transfusions - Immunosuppression ·

Infection-attributed deaths · Leukemia · Life-threatening

infections · Toxicity

\begin{abstract}
Background/Aims: Despite limited evidence for efficacy, granulocyte transfusions (GTX) are used to prevent and treat opportunistic infections in patients with neutropenia. Methods: Three hundred and seventy-three GTX given to 74 patients were assessed retrospectively. Results: GTX were discontinued because of clinical improvement more often in patients with severe infections than in patients without severe infections ( 27 vs. $12 \% ; p \leq 0.002$ ), whereas deaths resulted in discontinuation of GTX therapy less often in patients with severe infections than without (8 vs. $39 \% ; p \leq$ 0.002). Patients who died by 12 weeks after GTX initiation were more likely to have leukemia $(p=0.03)$, not to have recovery of neutrophil counts $(p<0.0001)$, and to have started GTX during a critical care unit stay $(p<0.001)$. Uses of granulocyte colony-stimulating factor $(p \leq 0.02)$ and interferon- $\gamma$ $(p \leq 0.04)$ were more common in patients who survived. In
\end{abstract}

\section{KARGER}

E-Mail karger@karger.com

www.karger.com/aha patients with comorbidities (31\%; odds ratio, OR, 12.6; 95\% confidence interval, $\mathrm{Cl}, 2.4-65.7 ; \mathrm{p} \leq 0.003)$, GTX was started in the critical care unit (OR 8.8; 95\% Cl 2.5-30.9; $\mathrm{p}<0.001)$, and a high total bilirubin level at the end of GTX (OR 2.1;95\% Cl 1.1-4.2; $p=0.03$ ) had a higher probability of death 12 weeks after GTX therapy commenced. Conclusions: The possibility that a niche population may benefit from GTX requires further assessment.

(c) 2013 S. Karger AG, Basel

\section{Introduction}

Infections continue to be a serious impediment to favorable outcomes for cancer patients undergoing cytotoxic antineoplastic therapy $[1,2]$. Despite the availability of modern antimicrobial drugs, opportunistic bacterial, viral, and fungal infections are prominent causes of death during and after treatment with new-generation oncology drugs $[3,4]$. Over the past 20 years, the rise in

There is no conflict of interest for A.S., G.R., J.Z., F.A.A. and A.P.
(C) 2013 S. Karger AG, Basel

0001-5792/14/1311-0050\$39.50/0 
drug-resistant bacteria, the continued presence of difficult-to-treat invasive fungal disease, and the occurrence of life-threatening end-organ damage due to less drugresponsive viral infections have posed daunting challenges for survival in severely immunosuppressed patients with myeloid or lymphoid neoplasms [5-7]. Although the incidence of life-threatening infections declined in this population following the introduction of prophylaxis with recombinant myeloid growth factors [8, 9], many neutropenic patients with advanced or relapsed hematologic malignancies do not respond to these agents [1012]. Granulocyte transfusions (GTX) can restore granulocyte counts and thus theoretically decrease the risk of infection in such patients. However, whether GTX can improve outcome in neutropenic patients with established infections as observed by some [13] still remains uncertain.

The first documented attempt to reverse neutropenia by using donor granulocytes was reported in the early 1930s [14]. Since then, phase II [15] and phase III [1620] clinical trials of GTX in neutropenic patients with infection have provided inconclusive results. Problems obtaining adequate concentrations of granulocytes and concerns about undesirable reactions to granulocytes have largely been addressed by technological advances $[21,22]$, but recent large randomized trials of prophylaxis with high concentrations of irradiated granulocytes from healthy donors did not show definitive benefit from GTX in preventing serious infections in patients undergoing hematopoietic stem cell transplantation $[23,24]$.

To add to the peer-reviewed observational studies using GTX to treat severe infections during neutropenia, we studied the impact of GTX therapy on infections in neutropenic patients with hematologic malignancies at a National Institutes of Health-designated comprehensive cancer center. We sought to identify patient responses, toxicity and disease factors that could be used to predict the outcome of GTX therapy.

\section{Patients and Methods}

\section{Study Design}

We retrospectively reviewed the records of neutropenic cancer patients with infections who received GTX between 2004 and 2007 at The University of Texas MD Anderson Cancer Center. Patients were identified using blood bank and apheresis laboratory data. Patient and laboratory data were retrieved from patient charts and computerized hospital databases. Institutional review board approval was obtained for the study, and the requirement for informed consent was waived.

Granulocyte Transfusions in Cancer

Patients with Infections
Treatment response was determined by a treating primary hematologist or bone marrow transplant faculty; consulting an infectious disease and pulmonary faculty (when present), and reports from an institutional radiology department and microbiology laboratory. In addition, all treatment responses including death associated with progressive invasive fungal disease were independently reassessed by the study team and the principal investigator.

\section{Granulocyte Collection and Administration}

GTX donors were recruited from relatives, friends of patients and community volunteers for infectious diseases according to regulatory requirements for allogeneic donors as outlined by the US Food and Drug Administration. They were given a single dose of dexamethasone ( $8 \mathrm{mg}$ p.o.) and granulocyte colony-stimulating factor (G-CSF; $5 \mu \mathrm{g} / \mathrm{kg}$ body weight s.c.) $24 \mathrm{~h}$ before neutrophils were collected. The centrifuge leukapheresis yield median given to each recipient was $5.6 \times 10^{10}\left(\right.$ range, $\left.4.0-10 \times 10^{10}\right)$ granulocytes per transfusion dose. Granulocytes were crossmatched with a sample of the patient's plasma for ABO compatibility. Patients were not screened for leukocyte antibodies, and leukocyte compatibility testing was not routinely performed at our center. The transfusions were irradiated with $25 \mathrm{cGy}$ prior to release for transfusion, following the standard transfusion procedures.

Transfusions were given daily or on alternating days depending on the availability of donors. The methods are described elsewhere in detail [13]. Indications to start GTX therapy as indicated by treating physicians' note included neutropenic infection, antimicrobial failure after $>72 \mathrm{~h}$ of therapy, and persistent febrile $\left(\geq 38.1^{\circ} \mathrm{C}\right)$ neutropenia. Reasons for GTX discontinuation included recovery of neutrophil counts, clinical improvement, death, donor unavailability, severe adverse events, e.g. respiratory complications including dyspnea, bronchospasm and/or wheezing, persistent cough, need for supplemental oxygen therapy, or worsening infection. All patients were hospitalized for their infections at the time of GTX.

\section{Definitions}

Neutropenia was defined as an absolute neutrophil count of $<500$ cells/ $\mu$ l. Bacterial, fungal, or viral infections were considered to have contributed to death when an organism was isolated from postmortem heart, blood, or sterile tissues in the presence of histologic evidence of invasive disease.

Infections were considered severe in any of the following circumstances: (a) bacterial or fungal bloodstream infection with signs and symptoms of sepsis or impending sepsis, (b) septic shock, (c) disseminated bacterial and/or fungal disease involving two noncontiguous organs, (d) infection involving the central nervous system, (e) pneumonia with respiratory compromise, or (f) end-stage organ disease due to opportunistic viruses such as cytomegalovirus (CMV), human herpesvirus 6, or varicella zoster virus $[7,12,13]$. Patients were considered not to have severe infections in the absence of all of the aforementioned conditions; if an infection was not clinically and/or microbiologically documented or if there may have been a noninfectious etiology of fever, pulmonary infiltrates, or mass-like lesions in a high-risk setting, such as neutropenic patients with refractory leukemia undergoing salvage chemotherapy.

Responses to and failure of therapy and noninfectious deaths have been defined elsewhere $[7,12,13]$. Death was also attributed to infection when there was no clinical response to appropriate 
antimicrobial therapy and no other known terminal event such as myocardial infarction, intracranial hemorrhage, or pulmonary embolism had occurred.

\section{Statistical Methods}

Descriptive statistics including medians and ranges were calculated for patient, disease, and treatment characteristics and outcomes. Patients were stratified for the following comparisons: severe infection versus not, and alive versus dead by 4 and 12 weeks. Categorical variables were compared by $\chi^{2}$ or Fisher's exact tests, and continuous variables were compared by Wilcoxon rank-sum tests. Multiple logistic regression analysis was applied to identify the prognostic factors for the outcomes in patients with severe infection and death from the start of GTX therapy. All tests were two sided with a significance level of 0.05 . Statistical analyses were performed using SAS version 9.1 software (SAS Institute Inc., Cary, N.C., USA).

\section{Results}

We identified 74 neutropenic patients with infection who received GTX. The median duration of neutropenia before GTX was 30 (range, 2-99) days. The patients received a median of 4 (range, 1-50) GTX.

Table 1 summarizes patient, disease, and treatment characteristics. Fifty-eight percent received corticosteroids (median cumulative prednisone dose $500 \mathrm{mg}$ ) within 30 days prior to GTX, and in 32\% steroids were continued during GTX. Eighty-nine percent had received recombinant cytokines 30 days prior to GTX and in 68\% they were maintained during GTX. The median APACHE (Acute Physiology and Chronic Health Evaluation) II score was high (16; range, 7-37). Forty-nine percent of the patients were in a critical care unit when GTX commenced; the median stay was 10 (range, 1-30) days before GTX. Forty-one percent were receiving assisted mechanical ventilation when GTX commenced.

Among patients with documented infections, some patients had more than one pathogen: 42 (57\%) had bacteremia (13 enterococci, 11 coagulase-negative staphylococci, 8 Pseudomonas aeruginosa, 7 methicillin-resistant Staphylococcus aureus, and 5 Stenotrophomonas maltophilia). Thirty-three (45\%) had invasive fungal disease due to Aspergillus spp. $(\mathrm{n}=10)$, candidemia $(\mathrm{n}=8)$, fusariosis $(n=5)$, or zygomycosis $(n=5)$. Among the 10 patients (14\%) with viral disease, 5 had disseminated or locally advanced drug-refractory herpes simplex virus infection, 4 had severe parainfluenza virus infection, and 3 had CMV disease. GTX were given in 36 patients (49\%) with nonsevere infections, including $8(11 \%)$ with persistent febrile neutropenia with sterile cultures.
In 34 patients (46\%), GTX were discontinued due to clinical response and neutrophil count recovery. GTXrelated toxicity was observed in 8 patients (11\%): respiratory complications in $6(8 \%)$ and fever in $2(3 \%)$. In $5(7 \%)$ of the 8 patients, GTX were discontinued owing to serious toxicity. Twenty-two patients (30\%) died of advanced refractory leukemia, whereas infection alone was considered the cause of death in 17 patients (23\%).

\section{Univariate Analysis}

When patients with and without severe infections were compared, fewer patients with severe infections had received corticosteroids during GTX (19 vs. 39\%; p s $0.07)$. Similarly, a lower proportion with severe infection died within 4 weeks ( 26 vs. $57 \%$; $\mathrm{p} \leq 0.01$ ) after GTX initiation. Furthermore, clinical improvement resulted in discontinuation of GTX therapy significantly more often in patients with than without severe infections (27 vs. $12 \%$; $\leq 0.002$ ), whereas deaths resulted in discontinuation of GTX therapy more often in patients without than with severe infections ( 39 vs. $8 \%$; $p=0.002$ ). Recovery of peripheral neutrophil counts leading to GTX discontinuation did not differ significantly between the two groups ( 23 vs. $35 \%$; $p>0.5$ ).

Table 1 shows a comparison of patients by whether they had or had not died by 4 and 12 weeks after GTX commencement. The patients who died by 4 weeks were significantly more likely to have comorbidities ( $\mathrm{p} \leq 0.001$ ), to have received corticosteroids during GTX ( $<<0.001)$, and to have high APACHE II scores $(p \leq 0.002)$. The patients who died by 12 weeks were significantly more likely to have acute leukemia ( $\mathrm{p} \leq$ 0.03 ), not to have received G-CSF ( $p \leq 0.02)$, not to have received interferon (IFN)- $\gamma(\mathrm{p} \leq 0.04)$, not to have recovery of neutrophil counts ( $p<0.0001)$, and to have GTX started in the critical care unit $(\mathrm{p}<0.001)$. Patients who died by 12 weeks had significantly higher median serum creatinine levels ( $p \leq 0.04)$ at the end of GTX, and those who died by 4 or 12 weeks had higher median total bilirubin levels before and at the end of GTX ( $\mathrm{p} \leq$ 0.002 ; table 2).

\section{Multivariate Analysis}

In the multivariate analysis, comorbidities (odds ratio, OR, 13.5; 95\% confidence interval, CI, 2.1-89.0; $\mathrm{p}=$ 0.007), corticosteroid therapy during GTX (OR 13.2; 95\% CI 1.6-106.6; $\mathrm{p}=0.016)$, and starting GTX in the critical care unit (OR 13.6; 95\% CI 2.6-70.4; $\mathrm{p}=0.002$ ) predicted death by 4 weeks after GTX commencement. Elevated total bilirubin levels at the end of GTX (OR
Acta Haematol 2014;131:50-58 DOI: $10.1159 / 000351174$
Safdar/Rodriguez/Zuniga/Al Akhrass/ Pande 
Table 1. Patient, disease, and treatment characteristics by survival outcome 4 and 12 weeks following commencement of healthy-donor GTX

\begin{tabular}{|c|c|c|c|c|c|c|c|}
\hline Characteristics & $\begin{array}{l}\text { Total } \\
\text { patients } \\
(\mathrm{n}=74)\end{array}$ & $\begin{array}{l}\text { Alive at } \\
4 \text { weeks } \\
(n=40)\end{array}$ & $\begin{array}{l}\text { Dead at } \\
4 \text { weeks } \\
(n=34)\end{array}$ & $\begin{array}{l}\mathrm{p} \\
\text { value }\end{array}$ & $\begin{array}{l}\text { Alive at } \\
12 \text { weeks } \\
(\mathrm{n}=26)\end{array}$ & $\begin{array}{l}\text { Dead at } \\
12 \text { weeks } \\
(n=47)\end{array}$ & $\begin{array}{l}\mathrm{p} \\
\text { value }\end{array}$ \\
\hline Age, years & $56(12-81)$ & $56(19-76)$ & $56(12-81)$ & 0.3 & $56(19-78)$ & $54(12-81)$ & 0.8 \\
\hline Male & $43(58 \%)$ & $20(50 \%)$ & $23(68 \%)$ & 0.1 & $12(46 \%)$ & $30(64 \%)$ & 0.1 \\
\hline Ethnicity & & & & 0.6 & & & 0.8 \\
\hline White & $53(72 \%)$ & $29(73 \%)$ & $24(71 \%)$ & & $18(69 \%)$ & $34(72 \%)$ & \\
\hline Non-Hispanic Black & $5(7 \%)$ & $4(10 \%)$ & $1(3 \%)$ & & $3(12 \%)$ & $2(4 \%)$ & \\
\hline Hispanic & $8(11 \%)$ & $4(10 \%)$ & $4(12 \%)$ & & $3(12 \%)$ & $5(11 \%)$ & \\
\hline Middle Eastern & $4(5 \%)$ & $1(3 \%)$ & $3(9 \%)$ & & $1(4 \%)$ & $3(6 \%)$ & \\
\hline Eastern Asian & $4(5 \%)$ & $2(5 \%)$ & $2(6 \%)$ & & $1(4 \%)$ & $3(6 \%)$ & \\
\hline Underlying malignancy & & & & 0.3 & & & 0.03 \\
\hline Acute leukemia & $56(76 \%)$ & $28(70 \%)$ & $28(82 \%)$ & & $17(65 \%)$ & $38(81 \%)$ & \\
\hline Chronic leukemia & $10(14 \%)$ & $5(13 \%)$ & $5(15 \%)$ & & $3(12 \%)$ & $7(15 \%)$ & \\
\hline Lymphoma & $1(1 \%)$ & $1(3 \%)$ & 0 & & 0 & $1(2 \%)$ & \\
\hline Other & $7(9 \%)$ & $6(15 \%)$ & $1(3 \%)$ & & $6(23 \%)$ & $1(2 \%)$ & \\
\hline Malignancy status & $70(95 \%)$ & $37(53 \%)$ & $33(47 \%)$ & 0.9 & $24(34 \%)$ & $45(64 \%)$ & 0.7 \\
\hline Relapsed or refractory & $59(84 \%)$ & $32(86 \%)$ & $27(82 \%)$ & & $19(79 \%)$ & $39(87 \%)$ & \\
\hline Active & $4(6 \%)$ & $2(5 \%)$ & $2(6 \%)$ & & $2(8 \%)$ & $2(4 \%)$ & \\
\hline Complete or partial remission & $6(9 \%)$ & $3(8 \%)$ & $3(9 \%)$ & & $3(13 \%)$ & $3(7 \%)$ & \\
\hline Stable disease & $1(1 \%)$ & 0 & $1(3 \%)$ & & 0 & $1(2 \%)$ & \\
\hline Comorbidities & $23(31 \%)$ & $7(30 \%)$ & $16(70 \%)$ & 0.001 & $2(9 \%)$ & $21(91 \%)$ & $<0.001$ \\
\hline Diabetes mellitus & $12(16 \%)$ & $6(50 \%)$ & $6(50 \%)$ & 0.2 & $2(17 \%)$ & $10(83 \%)$ & \\
\hline Renal failure & $3(4 \%)$ & 0 & $3(100 \%)$ & & 0 & $3(100 \%)$ & \\
\hline CAD or $\mathrm{CHF}$ & $5(7 \%)$ & $1(20 \%)$ & $4(80 \%)$ & & 0 & $5(100 \%)$ & \\
\hline Splenectomy & $3(4 \%)$ & 0 & $3(100 \%)$ & & 0 & $3(100 \%)$ & \\
\hline Chemotherapy 30 days prior to GTX & $70(95 \%)$ & $38(95 \%)$ & $32(94 \%)$ & 1 & $25(96 \%)$ & $44(94 \%)$ & 1 \\
\hline Hematopoietic transplantation & $18(24 \%)$ & $9(23 \%)$ & $9(26 \%)$ & 0.7 & $7(27 \%)$ & $10(21 \%)$ & 0.6 \\
\hline GVHD treatment & $2(11 \%)$ & 0 & $2(6 \%)$ & 0.2 & 0 & $2(4 \%)$ & 0.5 \\
\hline Corticosteroids 30 days prior to GTX & $43(58 \%)$ & $18(45 \%)$ & $25(74 \%)$ & 0.01 & $14(54 \%)$ & $28(62 \%)$ & 0.6 \\
\hline Dose, $\mathrm{mg}$ & $500(27-7,733)$ & $261(53-2,133)$ & $625(27-7,733)$ & 0.3 & $250(53-2,133)$ & $659(27-7,733)$ & 0.2 \\
\hline Corticosteroids during GTX & $23(32 \%)$ & $5(13 \%)^{1}$ & $18(53 \%)$ & $<0.001$ & & & \\
\hline Dose, $\mathrm{mg}$ & $266(4-1,625)$ & $100(4-275)$ & $308(13-1,625)$ & 0.09 & $53(4-275)$ & $266(13-1,625)$ & 0.2 \\
\hline Growth factors 30 days prior to GTX & $66(89 \%)$ & $37(93 \%)$ & $29(85 \%)$ & 0.5 & $26(100 \%)$ & $39(83 \%)$ & 0.04 \\
\hline Patients on G-CSF & $52(70 \%)$ & $30(75 \%)$ & $22(65 \%)$ & 0.3 & $23(88 \%)$ & $29(62 \%)$ & 0.02 \\
\hline Doses, $\mathrm{n}$ & $7(1-38)$ & $7(1-35)$ & $6(1-38)$ & 0.6 & $6(1-30)$ & $8(1-38)$ & 0.4 \\
\hline Patients on GM-CSF & $25(34)$ & $14(35)$ & $11(32)$ & 0.8 & $9(35)$ & $16(34)$ & 0.9 \\
\hline Doses, $\mathrm{n}$ & $4(1-14)$ & $4(1-14)$ & $5(2-11)$ & 0.4 & $3(2-12)$ & $4(1-14)$ & 0.5 \\
\hline Patients on IFN- $\gamma$ & $3(4 \%)$ & $3(8 \%)$ & 0 & 0.2 & $3(12 \%)$ & 0 & 0.04 \\
\hline Doses, $\mathrm{n}$ & $7(1-15)$ & $3(2-4)$ & NA & & $3(2-4)$ & NA & \\
\hline Growth factors during GTX & $50(68 \%)$ & $27(68 \%)$ & $23(68 \%)$ & 0.9 & $19(73 \%)$ & $30(64 \%)$ & 0.4 \\
\hline Patients on G-CSF & $50(68 \%)$ & $27(68 \%)$ & $23(68 \%)$ & 0.9 & $19(73 \%)$ & $30(64 \%)$ & 0.4 \\
\hline Doses, $\mathrm{n}$ & $3(1-38)$ & $3(1-18)$ & $3(1-38)$ & 0.6 & $3(1-17)$ & $3(1-38)$ & 0.9 \\
\hline Patients on GM-CSF & $24(32 \%)$ & $13(33 \%)$ & $11(32 \%)$ & 0.9 & $9(35 \%)$ & $15(32 \%)$ & 0.8 \\
\hline Doses, $\mathrm{n}$ & $2(1-21)$ & $2(1-17)$ & $2(1-21)$ & 0.8 & $2(1-17)$ & $2(1-21)$ & 0.7 \\
\hline Patients on IFN- $\gamma$ & $4(5 \%)$ & $2(5 \%)$ & $2(6 \%)$ & 1 & $1(4 \%)$ & $3(6 \%)$ & 1 \\
\hline Doses, $\mathrm{n}$ & $7(1-15)$ & $3(1-4)$ & $11(6-15)$ & 0.3 & $1(1-1)$ & $6(4-15)$ & 0.4 \\
\hline APACHE II score at start of GTX & $16(7-37)$ & $15(7-34)$ & $20(11-37)$ & 0.002 & $15(7-34)$ & $17(9-37)$ & 0.05 \\
\hline CMV reactivation assessment ${ }^{2}$ & $71(96 \%)$ & $38(95 \%)$ & $33(97 \%)$ & 1 & $24(92 \%)$ & $46(98 \%)$ & 1 \\
\hline CMV reactivation & $20(28 \%)$ & $13(34 \%)$ & $7(21 \%)$ & 0.2 & $10(42 \%)$ & $10(22 \%)$ & 0.08 \\
\hline Neutropenia & $74(100 \%)$ & $40(100 \%)$ & $34(100 \%)$ & & $26(100 \%)$ & $47(100 \%)$ & \\
\hline Duration, days & $30(2-60)$ & $26(2-60)$ & $30(3-99)$ & 0.3 & $30(3-32)$ & $30(2-99)$ & 0.9 \\
\hline Lymphopenia & $70(96 \%)$ & $38(54 \%)$ & $32(46 \%)$ & 0.6 & $25(36 \%)$ & $44(64 \%)$ & 0.6 \\
\hline Duration, days & $30(3-60)$ & $31(3-60)$ & $31(5-40)$ & 0.5 & $31(3-41)$ & $31(5-60)$ & 0.9 \\
\hline Indication for GTX & $73(99 \%)$ & $39(53 \%)$ & $34(47 \%)$ & 0.3 & $25(35 \%)$ & $47(65 \%)$ & 0.002 \\
\hline Neutropenia without fever & $1(1 \%)$ & $1(3 \%)$ & 0 & & $1(4 \%)$ & 0 & \\
\hline Persistent febrile neutropenia & $8(11 \%)$ & $6(15 \%)$ & $2(6 \%)$ & & $5(20 \%)$ & $3(6 \%)$ & \\
\hline Progressive severe infection ${ }^{3}$ & $28(38 \%)$ & $12(31 \%)$ & $16(47 \%)$ & & $3(12 \%)$ & $24(51 \%)$ & \\
\hline Neutropenic infection & $36(49 \%)$ & $20(51 \%)$ & $16(47 \%)$ & & $16(64 \%)$ & $20(43 \%)$ & \\
\hline GTX, n & $4(1-50)$ & $4(1-50)$ & $4(1-32)$ & 0.6 & $4(1-50)$ & $4(1-32)$ & 0.7 \\
\hline
\end{tabular}

Granulocyte Transfusions in Cancer Patients with Infections
Acta Haematol 2014;131:50-58 DOI: $10.1159 / 000351174$ 
Table 1 (continued)

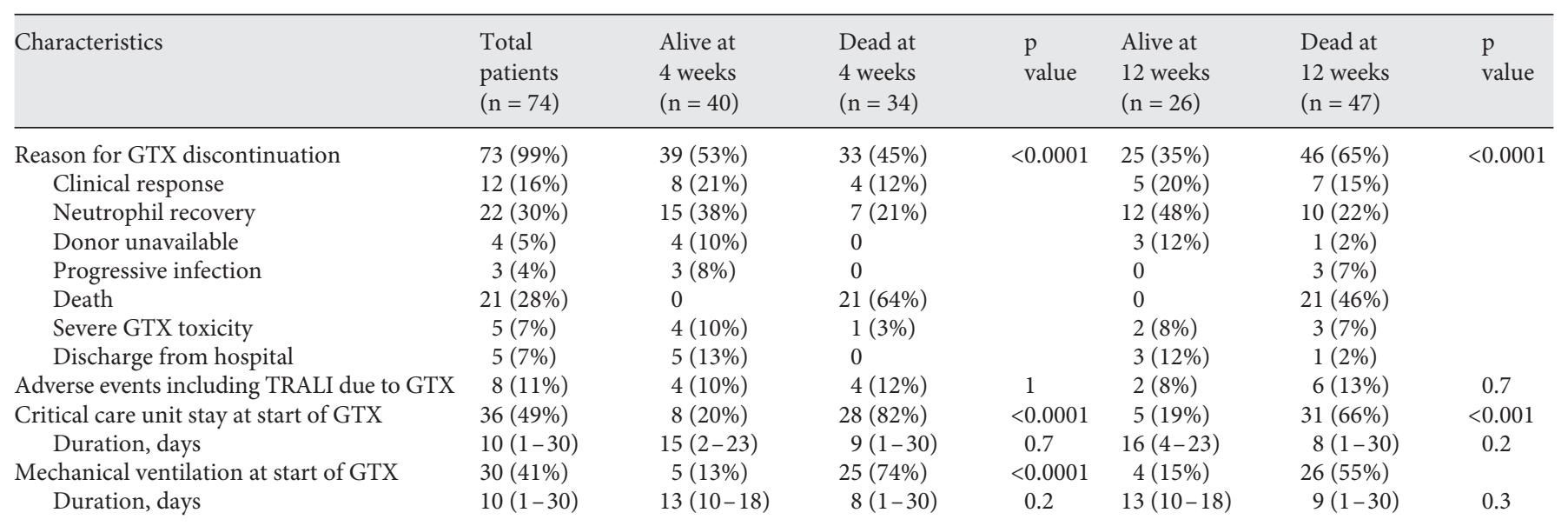

Numbers of patients or medians (ranges) are shown. Malignancy status was available in 69 patients and lymphopenia status was known in 73 patients at the time GTX commenced. Transfusion-related acute lung injury (TRALI) in patients undergoing mechanical ventilation was assessed by the following parameters: (1) rapid, unexplained desaturation, or (2) acute respiratory decompensation duration or immediately after GTX therapy, and/or (3) evidence of GTX-related difficulty in maintaining optimum gas exchange. $\mathrm{CAD}=$ Coronary artery disease $\mathrm{CHF}=$ congestive heart failure; GVHD = graft-versus-host disease.
${ }^{1}$ Whether or not corticosteroids were given during GTX therapy was known for 73 patients overall and 39 patients alive at 4 weeks.

${ }^{2}$ Results of CMV antigenemia assays or polymerase chain reaction within 30 days of GTX therapy were available in 71 patients.

${ }^{3}$ Infection was considered progressive if appropriate antimicrobial therapy for $>72 \mathrm{~h}$ failed.

Table 2. Laboratory values in GTX recipients

\begin{tabular}{|c|c|c|c|c|c|c|c|}
\hline Characteristics & $\begin{array}{l}\text { Total } \\
\text { patients } \\
(\mathrm{n}=74)\end{array}$ & $\begin{array}{l}\text { Alive at } \\
4 \text { weeks } \\
(n=40)\end{array}$ & $\begin{array}{l}\text { Dead at } \\
4 \text { weeks } \\
(n=34)\end{array}$ & $\mathrm{p}$ value & $\begin{array}{l}\text { Alive at } \\
12 \text { weeks } \\
(\mathrm{n}=26)\end{array}$ & $\begin{array}{l}\text { Dead at } \\
12 \text { weeks } \\
(\mathrm{n}=47)\end{array}$ & $\mathrm{p}$ value \\
\hline Start of GTX & $0.9(0.4-6)$ & $0.9(0.4-2.6)$ & $0.9(0.4-6)$ & 0.4 & $0.9(0.4-2.6)$ & $0.8(0.4-6)$ & 0.8 \\
\hline During GTX & $0.9(0.4-6)$ & $0.8(0.4-2.3)$ & $1.1(0.6-3.3)$ & 0.02 & $0.8(0.4-2.3)$ & $1.0(0.4-3.3)$ & 0.1 \\
\hline End of GTX & $0.9(0.4-6)$ & $0.8(0.4-2.9)$ & $1.5(0.5-5.3)$ & 0.001 & $0.7(0.4-2.9)$ & $1.2(0.4-5.3)$ & 0.04 \\
\hline Start of GTX & $1.2(0.2-31)$ & $0.7(0.2-4.7)$ & $2.6(0.2-31.0)$ & $<0.0001$ & $0.65(0.2-4.7)$ & $1.6(0.2-31)$ & 0.002 \\
\hline During GTX & $1.1(0.2-22.1)$ & $1(0.2-2.8)$ & $2.8(0.2-22.1)$ & 0.02 & $0.9(0.3-2.8)$ & $1.3(0.2-22.1)$ & 0.3 \\
\hline End of GTX & $1.5(0.2-21.1)$ & $0.9(0.2-3.5)$ & $3.4(0.3-21.1)$ & $<0.0001$ & $0.9(0.2-3.5)$ & $2.4(0.2-21.1)$ & 0.001 \\
\hline \multicolumn{8}{|c|}{ Albumin level, g/dl } \\
\hline Start of GTX & $2.5(1.3-3.9)$ & $2.5(2-4)$ & $2.3(1-26)$ & 0.03 & $2.3(2-4)$ & $2.3(1.2-26)$ & 0.5 \\
\hline During GTX & $2.5(1.3-3.9)$ & $2.6(2-4)$ & $2.1(1-4)$ & 0.05 & $2.6(2-4)$ & $2.5(1.4-3.9)$ & 0.8 \\
\hline End of GTX & $26.5(15-5,924)$ & $25(12-109)$ & $36(2-5,924)$ & 0.04 & $25(12-109)$ & $27(2-5,924)$ & 0.3 \\
\hline \multicolumn{8}{|c|}{ Aspartate aminotransferase, IU/1 } \\
\hline Start of GTX & $26(10-233)$ & $21(10-217)$ & $26(10-233)$ & 0.2 & $19(10-114)$ & $26(10-233)$ & 0.3 \\
\hline During GTX & $30(10-2,165)$ & $27(10-155)$ & $30(12-2,165)$ & 0.6 & $39(10-118)$ & $30(10-2,165)$ & 0.9 \\
\hline End of GTX & $29(10-15,000)$ & $20(10-130)$ & $56(10-15,000)$ & 0.005 & $20(10-130)$ & $36(10-15,000)$ & 0.05 \\
\hline
\end{tabular}


$2.1 ; 95 \%$ CI 1.1-4.2; $\mathrm{p}=0.026$ ), comorbidities (OR 12.6; 95\% CI 2.4-65.7; $\mathrm{p}=0.003)$, and starting GTX in the critical care unit (OR 8.8; 95\% CI 2.5-30.9; p < 0.001) predicted death by 12 weeks after GTX commencement.

\section{Discussion}

In this relatively large cohort of severely immunosuppressed cancer patients who received GTX from healthy donors, GTX were well tolerated. Patients with documented severe infections had significantly better survival rates when they received GTX than those who did not have severe infection. This may suggest that either the benefits of GTX are greater in the presence of documented severe bacterial or fungal infection or that the adverse effects of GTX have a greater impact in a group with lesswell-defined infection. These survival benefits were only seen when GTX were given prior to disease progression resulting in multisystem failure requiring mechanical ventilation and a critical care unit stay. Adjuvant recombinant cytokines such as G-CSF and IFN- $\gamma$ were commonly used during GTX in patients who had clinical responses. Patients with renal failure or other comorbid conditions, those treated with corticosteroids during GTX, and those in whom hyperbilirubinemia occurred before and after GTX had a significantly increased risk for death. The incidence of GTX-related adverse events was low (11\%), and only 7\% of patients had severe GTX-associated toxicity that led to discontinuation of GTX.

Clinical use of GTX in patients with persistent neutropenia declined during the late 1980s and 1990s owing to improvements in antimicrobial drugs and other supportive care measures in conjunction with marginal and often unpredictable responses associated with transfusion of granulocyte concentrates [20]. The reasons for inconsistent clinical responses could include differences in any of the following: (a) patient selection, e.g. with or without comorbidities, liver dysfunction, or multisystem failure; (b) status of the underlying cancer, e.g. treatment-refractory disease, myeloid growth factor-refractory neutropenia; (c) indications for GTX therapy, e.g. established bacterial or fungal infection versus febrile neutropenia, persistent nonneutropenic fever, or fever of uncertain etiology; (d) GTX type, i.e. related versus HLA-matched unrelated donors; (e) protocols for donor priming, i.e, prednisone versus G-CSF plus steroids versus granulocyte macrophage (GM)-CSF alone or with steroids; (f) alloimmunization, i.e. existing anti-granulocyte antibodies or de novo development of antibodies against granulocytes during transfusions; (g) timing of transfusions, i.e. early intervention versus salvage therapy given late in the course of infection; (h) GTX-associated toxicity resulting in truncated, suboptimal immune supplementation, e.g. HLA class II antibody-mediated transfusion-related acute lung injury [25] or persistent high fever; (i) transfusion-related infections, e.g. CMV [26] or human herpesvirus 6 infections [27]; (j) availability of donors; (k) nonreimbursable costs, and, importantly, (l) treating physicians' preferences. Similarly, in our report, a number of factors stated above had played a role in the use of GTX and termination of granulocyte replacement therapy.

During the 1950s and 1960s, granulocytes for transfusions were often obtained from patients with chronic granulocytic leukemia, raising several concerns: (a) engraftment of leukemia stem cells; (b) higher toxicity compared with GTX from healthy donors (33 vs. $12 \%$, respectively; $\mathrm{p} \leq 0.05$ ) [28], and (c) graft-versus-host disease in recipients of unirradiated leukemia cell transfusions [28]. In the past 3 decades, granulocytes for transfusion in humans have been restricted to those from healthy donors with no evidence of various communicable diseases (as mandated by the US Food and Drug Administration). We did not observe unexpected GTX toxicity in 74 patients, including patients in whom up to 50 transfusions were given.

The likelihood of patients becoming afebrile during GTX has previously been noted to be significantly higher in those with established or clinically probable bacterial or fungal infections than in neutropenic patients with fever of uncertain etiology [28]; our findings were in keeping with this observation as clinical response, including resolution of fever, was prominent in patients with documented severe infection. Whereas in those with febrile neutropenia without evidence of bacterial or fungal disease, no such benefit was observed. This was similar to observations in oncology patients with treatment-refractory severe bacterial sepsis: GTX were feasible, were safe, and reduced the death rate [29]. In a study of 59 pediatric patients who received 778 GTX for bacterial and/or invasive fungal diseases during neutropenia owing to conventional chemotherapy, hematopoietic stem cell transplantation conditioning, or the underlying cancer, their high response rate with early institution of GTX in neutropenic children and young adults with known infections was in agreement with our observations in adults [30]. Adverse reactions were rare; the most common was fever (14\%), while mild pulmonary toxicity was seen in only 1 patient [30]. 
Delayed institution of GTX therapy for advanced infection, as was demonstrated in our study, has been reported by others, but GTX given early in the course of severe bacterial sepsis in 27 neutropenic children with cancer resulted in a response rate of $>90 \%$ and a favorable toxicity profile [31].

In our study, patients with severe infections had significantly better outcomes compared with those who received GTX for nonspecific febrile neutropenia or other conditions that may have been misinterpreted as infection (table 1). Giving GTX early in the course of infection and giving GTX during cancer remission or myeloid recovery have in fact been favorable predictors of response in a number of reports [28-34]. In the current report, starting GTX in the critical care unit, an indicator itself of advanced infection and possibly delayed GTX therapy, especially among patients requiring assisted ventilatory support, increased the probability of death by nearly 9 -fold, whereas lack of marrow recovery and refractory underlying cancer did not predict death, likely because most patients received GTX during refractory neutropenia and only $10 \%$ had cancer that was in remission or stable. However, due to the retrospective nature of this nonrandomized study, factors other than GTX may have played a role in improving outcome among patients with documented severe infections.

Due to the constant shortage of related donors, in a study reported in 2002, the toxicity and efficacy of GTX from related and unrelated (community) donors were comparable, which is important for expanding the pool of potential donors [35]. In our study, there were no differences in toxicity or outcomes among patients given GTX from related or unrelated donors (data not shown).

Technological advances have increased the number of granulocytes that can be harvested from each donor. Modern centrifuge technology yields superior granulocyte concentrates, even from nonimmune-primed donors, compared with historical filtration methods [36, 37]. In addition, donor immune priming further increases granulocyte yields. Immune priming increases the number of young and premature granulocytes in the donors' peripheral circulation, in turn resulting in elevated absolute neutrophil counts in the recipients' peripheral blood. Priming of donors with G-CSF, the most frequently used agent, is generally well tolerated; the most common side effects are bone pain, malaise, and paresthesia. In a study that had a median follow-up of 4.5 (range, 0.8 7.7) years, donors had no delayed or unexpected toxicity due to G-CSF priming [38]. In a study of 9 healthy adult donors who received G-CSF ( $16 \mu \mathrm{g} / \mathrm{kg} /$ day $)$ for priming, neutrophil and monocyte counts increased 10- and 2-fold, respectively, as expected [39]. However, a doubling of natural killer cells and activated T lymphocytes 4 days following G-CSF was not anticipated; furthermore, unexplained modifications of helper and suppressor lymphocyte subsets in the peripheral blood were noted, suggesting that careful review of immune priming methods is needed [39].

Priming with G-CSF plus dexamethasone, besides increasing the neutrophil yield, upregulates the expression of genes for multiple Toll-like receptors (TLR-2, TLR-4, TLR-5, and TLR-8) [40]. The resulting TLR-2- and TLR8 -mediated heightened response against microbes causes donor cells to produce large quantities of IL-8, which may increase the antimicrobial activity of the transfused donor granulocytes [40]. Donor granulocyte-mediated increase in IL-8 production may also exacerbate the systemic inflammatory response with potential deleterious consequences.

The response to GTX might also be increased by augmenting the immune system of the recipients. Recombinant myeloid growth factors are routinely given to severely neutropenic patients, and treatment with recombinant Th1 cytokines has been studied as a means to increase granulocyte and mononuclear cell functions, and augment antifungal responses [41]. In an earlier study, we assessed the feasibility of giving recombinant IFN- $\gamma 1 \mathrm{~b}$ to 20 patients receiving GTX for refractory invasive fungal disease and Pseudomonas sepsis; $70 \%$ also received GM-CSF [42]. It was encouraging to note that adverse events were grade III or less and resolved after cytokine treatment was discontinued. A complete/partial response or stabilization of progressive invasive fungal disease occurred in $60 \%$ of these severely immunosuppressed cancer patients [42]. In the current report, adjuvant G-CSF and IFN- $\gamma$ were significantly more commonly used during GTX in patients who had clinical responses. Further randomized studies to assess the therapeutic role of recombinant adjuvant cytokines with GTX are needed.

In summary, in 74 severely immunosuppressed adult patients with mostly refractory hematologic malignancies who received GTX to treat severe infections, the rates of toxicity and infection-related deaths were low. Giving GTX prior to patients' becoming critically ill was associated with an improved outcome. Appropriate selection of candidates for this therapy is essential. Our results suggest that patients with the following factors are less likely
56

Acta Haematol 2014;131:50-58 DOI: $10.1159 / 000351174$
Safdar/Rodriguez/Zuniga/Al Akhrass / Pande 
to benefit from GTX: (a) those in whom neutropenia persists without myeloid recovery, although in our report this was not significant in multivariate analysis; (b) those in whom corticosteroids cannot be discontinued, and (c) those with serious comorbidities such as renal failure or liver dysfunction. It also seems advisable to defer starting GTX therapy in critically ill patients; granulocyte concentrates have the potential to exacerbate the systemic inflammatory response by stimulating the production of IL-8. The preliminary data favor giving adjuvant GM-
CSF and IFN $-\gamma$ to patients while they are receiving GTX. Future studies focusing on GTX in high-impact niche population(s) are needed.

\section{Acknowledgment}

This study was supported by a core grant (CA16672) to the University of Texas MD Anderson Cancer Center from the National Cancer Institute and the National Institutes of Health.

\section{References}

1 Bodey GP, Buckley M, Sathe YS, Freireich EJ: Quantitative relationships between circulating leukocytes and infection in patients with acute leukemia. Ann Intern Med 1966;64: 328-340.

-2 Bodey GP, Nies BA, Freireich EJ: Multiple organism septicemia in acute leukemia: analysis of 54 episodes. Arch Intern Med 1965;116: 266-272.

- 3 Lin TS, Donohue KA, Byrd JC, Lucas MS, Hoke EE, Bengtson EM, Rai KR, Atkins JN, Link BK, Larson RA: Consolidation therapy with subcutaneous alemtuzumab after fludarabine and rituximab induction therapy for previously untreated chronic lymphocytic leukemia: final analysis of CALGB 10101. J Clin Oncol 2010;28:4500-4506.

-4 Sung L, Lange BJ, Gerbing RB, Alonzo TA, Feusner J: Microbiologically documented infections and infection-related mortality in children with acute myeloid leukemia. Blood 2007;110:3532-3539.

5 Safdar A, Rolston KV: Stenotrophomonas maltophilia: changing spectrum of a serious bacterial pathogen in patients with cancer. Clin Infect Dis 2007;45:1602-1609.

-6 Kontoyiannis DP, Lionakis MS, Lewis RE, Chamilos G, Healy M, Perego C, Safdar A, Kantarjian H, Champlin R, Walsh TJ, Raad II: Zygomycosis in a tertiary-care cancer center in the era of Aspergillus-active antifungal therapy: a case-control observational study of 27 recent cases. J Infect Dis 2005;191:13501360.

7 Safdar A, Rodriguez GH, Mihu CN, MoraRamos L, Mulanovich V, Chemaly RF, Champlin RE, Khouri I: Infections in non-myeloablative hematopoietic stem cell transplantation patients with lymphoid malignancies: spectrum of infections, predictors of outcome and proposed guidelines for fungal infection prevention. Bone Marrow Transplant 2010;45: 339-347.
8 Rowe JM, Neuberg D, Friedenberg W, Bennett JM, Paietta E, Makary AZ, Liesveld JL, Abboud CN, Dewald G, Hayes FA, Tallman MS, Wiernik PH, Eastern Cooperative Oncology Group: A phase 3 study of three induction regimens and of priming with GM-CSF in older adults with acute myeloid leukemia: a trial by the Eastern Cooperative Oncology Group. Blood 2004;103:479-485.

-9 Kern W, Aul C, Maschmeyer G, Kuse R, Kerkhoff A, Grote-Metke A, Eimermacher H, Kubica U, Wörmann B, Büchner T, Hiddemann W: Granulocyte colony-stimulating factor shortens duration of critical neutropenia and prolongs disease-free survival after sequential high-dose cytosine arabinoside and mitoxantrone (S-HAM) salvage therapy for refractory and relapsed acute myeloid leukemia. German AML Cooperative Group. Ann Hematol 1998;77:115-122.

10 Faderl S, Thomas DA, O’Brien S, GarciaManero G, Kantarjian HM, Giles FJ, Koller C, Ferrajoli A, Verstovsek S, Pro B, Andreeff M, Beran M, Cortes J, Wierda W, Tran N, Keating MJ: Experience with alemtuzumab plus rituximab in patients with relapsed and refractory lymphoid malignancies. Blood 2003; 101:3413-3415.

11 Keating MJ, Flinn I, Jain V, Binet JL, Hillmen P, Byrd J, Albitar M, Brettman L, Santabarbara P, Wacker B, Rai KR: Therapeutic role of alemtuzumab (Campath-1H) in patients who have failed fludarabine: results of a large international study. Blood 2002;99:3554-3561.

12 Safdar A, Rodriguez GH, De Lima MJ, Petropoulos D, Chemaly RF, Worth LL, Shpall EJ, Rolston KV, Raad II, Chan KW, Champlin RE: Infections in 100 cord blood transplantations: spectrum of early and late posttransplant infections in adult and pediatric patients 1996-2005. Medicine (Baltimore) 2007;86: 324-333.

13 Safdar A, Hanna H, Boktour M, Kontoyiannis D, Hachem R, Lichtiger B, Freireich EJ, Raad I: Impact of high-dose granulocyte transfusions in patients with cancer with candidemia. Cancer 2004;101:2859-2865.
14 Strumia MM: The effect of leukocytic cream injections in the treatment of neutropenias. Am J Med 1934;187:527-544.

15 Graw RG Jr, Herzig G, Perry S, Henderson ES Normal granulocyte transfusion therapy: treatment of septicemia due to gram-negative bacteria. N Engl J Med 1972;287:367-371.

16 Higby DJ, Yates JW, Henderson ES, Holland JF: Filtration leukapharesis for granulocyte transfusion therapy. Clinical and laboratory studies. N Engl J Med 1975;292:761-766.

17 Vogler WR, Winston EF: A controlled study of the efficacy of granulocyte transfusions in patients with neutropenia. Am J Med 1977;63: 548-555.

18 Alavi JB, Root RK, Djerassi I, Evans AE, Gluckman SJ, MacGregor RR, Guerry D, Schreiber AD, Shaw JM, Koch P, Cooper RA: A randomized clinical trial of granulocyte transfusions for infection in acute leukemia. N Engl J Med 1977;296:706-711.

19 Herzig RH, Herzig GP, Graw RG Jr, Bull MI, Ray KK: Successful granulocyte transfusion therapy for gram-negative septicemia. A prospectively randomized controlled study. N Engl J Med 1977;296:701-705.

20 Winston DJ, Ho WG, Gale RP: Therapeutic granulocyte transfusions for documented infections. A controlled trial in ninety-five infectious granulocytopenic episodes. Ann Intern Med 1982;97:509-515.

21 Engelfriet CO, Reesink HW: Granulocyte transfusions. Vox Sang 2000;79:59-96.

22 Vamvakas EC, Pineda AA: Meta-analysis of clinical studies of the efficacy of granulocyte transfusions in the treatment of bacterial sepsis. J Clin Apher 1996;11:1-9.

23 Hübel K, Carter RA, Liles WC, Dale DC, Price TH, Bowden RA, Rowley SD, Chauncey TR, Bensinger WI, Boeckh M: Granulocyte transfusion therapy for infections in candidates and recipients of HPC transplantation: a comparative analysis of feasibility and outcome for community donors versus related donors. Transfusion 2002;42:1414-1421. 
-24 Seidel MG, Peters C, Wacker A, Northoff H, Moog R, Boehme A, Silling G, Grimminger W, Einsele H: Randomized phase III study of granulocyte transfusions in neutropenic patients. Bone Marrow Transplant 2008;42: 679-684.

25 Sachs UJ, Wasel W, Bayat B, Bohle RM, Hat$\operatorname{tar}$ K, Berghöfer H, Reil A, Bux J, Bein G, Santoso S, Weissmann N: Mechanism of transfusion-related acute lung injury induced by HLA class II antibodies. Blood 2011;117:669677.

26 Bowden RA: Transfusion-transmitted cytomegalovirus infection. Hematol Oncol Clin North Am 1995;9:155-166.

-27 Chemaly RF, Torres HA, Hachem R, Kontoyiannis DP, Safdar A, Raad II: Human herpesvirus-6 DNAemia in immunosuppressed adult patients with leukemia at risk for mold infection. Haematologica 2008;93:157-158.

28 Lowenthal RM, Grossman L, Goldman JM, Storring RA, Buskard NA, Park DS, Murphy BC, Spiers AS, Galton DA: Granulocyte transfusions in treatment of infections in patients with acute leukaemia and aplastic anaemia. Lancet 1975;i:353-358.

29 Grigull L, Pulver N, Goudeva L, Sykora KW, Linderkamp C, Beilken A, Seidemann K, Schmid H, Welte K, Heuft HG: G-CSF mobilised granulocyte transfusions in 32 paediatric patients with neutropenic sepsis. Support Care Cancer 2006;14:910-916.

-30 Seidel MG, Minkov M, Witt V, Matthes-Martin S, Pötschger U, Worel N, Leitner G, Stary J, Gadner H, Peters C: Granulocyte transfusions in children and young adults: does the dose matter? J Pediatr Hematol Oncol 2009; 31:166-172.
Sachs UJ, Reiter A, Walter T, Bein G, Woessmann W: Safety and efficacy of therapeutic early onset granulocyte transfusions in pediatric patients with neutropenia and severe infections. Transfusion 2006;46:1909-1914.

32 Rutella S, Pierelli L, Sica S, Serafini R, Chiusolo P, Paladini U, Leone F, Zini G, D’Onofrio G, Leone G, Piccirillo N: Efficacy of granulocyte transfusions for neutropenia-related infections: retrospective analysis of predictive factors. Cytotherapy 2003;5:19-30.

33 Petersen FB, Buckner CD, Clift RA, Nelson N, Counts GW, Meyers JD, Thomas ED: Prevention of nosocomial infections in marrow transplant patients: a prospective randomized comparison of systemic antibiotics versus granulocyte transfusions. Infect Control 1986;7:586-592.

- 34 Mousset S, Hermann S, Klein SA, Bialleck H, Duchscherer M, Bomke B, Wassmann B, Böhme A, Hoelzer D, Martin H: Prophylactic and interventional granulocyte transfusions in patients with haematological malignancies and life-threatening infections during neutropenia. Ann Hematol 2005;84:734-741.

35 Hübel K, Carter RA, Liles WC, Dale DC, Price TH, Bowden RA, Rowley SD, Chauncey TR, Bensinger WI, Boeckh M: Granulocyte transfusion therapy for infections in candidates and recipients of HPC transplantation: a comparative analysis of feasibility and outcome for community donors versus related donors. Transfusion 2002;42:1414-1421.
36 Morse EE, Synder E, Blumberg N, Katz AJ: Analysis of two types of granulocyte transfusions in patients with acute leukemia and septicemia. Ann Clin Lab Sci 1982;12:106-110.

- 37 Briones MA, Josephson CD, Hillyer CD: Granulocyte transfusion: revisited. Curr Hematol Rep 2003;2:522-527.

38 Cesaro S, Chinello P, De Silvestro G, Marson P, Picco G, Varotto S, Pittalis S, Zanesco L: Granulocyte transfusions from G-CSF-stimulated donors for the treatment of severe infections in neutropenic pediatric patients with onco-hematological diseases. Support Care Cancer 2003;11:101-106.

39 Sica S, Rutella S, Di Mario A, Salutari P, Rumi C, Ortu la Barbera E, Etuk B, Menichella G, D'Onofrio G, Leone G: rhG-CSF in healthy donors: mobilization of peripheral hemopoietic progenitors and effect on peripheral blood leukocytes. J Hematother 1996;5:391397.

-40 Drewniak A, Tool AT, Geissler J, van Bruggen R, van den Berg TK, Kuijpers TW: Toll-like receptor-induced reactivity and strongly potentiated IL-8 production in granulocytes mobilized for transfusion purposes. Blood 2010;115:4588-4596.

41 Safdar A: Strategies to enhance immune function in hematopoietic transplantation recipients who have fungal infections. Bone Marrow Transplant 2006;38:327-337.

-42 Safdar A, Rodriguez G, Lichtiger B, Dickey BF, Kontoyiannis DP, Freireich EJ, Shpall EJ, Raad II, Kantarjian HM, Champlin RE: Recombinant interferon gammalb immune enhancement in 20 patients with hematological malignancies and systemic opportunistic infections treated with donor granulocyte transfusions. Cancer 2006;106:2664-2671. 